\title{
Application of over-the-scope clip for massive duodenal ulcer bleeding in a 4-year-old boy weighing $7.8 \mathrm{~kg}$
}

Efficacy of the over-the-scope clip (OTSC; Ovesco Endoscopy $\mathrm{GmbH}$, Tübingen, Germany) system has been described in the adult population [1 -4], very rarely in pediatric patients. Wright et al. reported a first-ever application of OTSC for pediatric patients weighing over $10 \mathrm{~kg}$ with gastrocutaneous fistula [5]. However, its indication for younger patients, those with lower weight, or other situations, such as refractory bleeding, remains unclear. Here, we describe the effective application of OTSC for temporary hemostasis of massive duodenal bleeding in a 4-year-old boy with the lowest weight ever reported ( $>$ Video 1 ).

The patient presented with growth impairment since birth. At age 4 years, he received steroid treatment for mesalazine-resistant ulcerative colitis. His physical status was fragile (height $85.1 \mathrm{~cm}$, weight $7.8 \mathrm{~kg}$ ). Upper gastrointestinal endoscopy was performed because of presence of tarry stools and severe anemia (hemoglobin $6.3 \mathrm{~g} / \mathrm{dL}$ ), and revealed massive bleeding of an open ulcer locat-

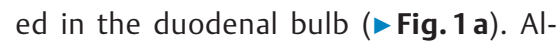
though conventional endoscopic therapies were effective for temporary hemostasis ( $>$ Fig. $\mathbf{1}$ b), arterial bleeding with hemorrhagic shock subsequently recurred five times. Enhanced computed tomography and open surgery were contraindicated owing to the child's poor physical status. Thus, OTSC was applied for the fifth recurrent bleeding episode after written informed consent had been obtained.
All procedures were performed under general anesthesia using an adult gastroscope with a waterjet function (GIFQ260J; Olympus, Tokyo, Japan). An OTSC (9 mm t-type) was successfully deployed at the bleeding site without any delivery difficulties in the duodenum ( $>$ Fig. 1c).

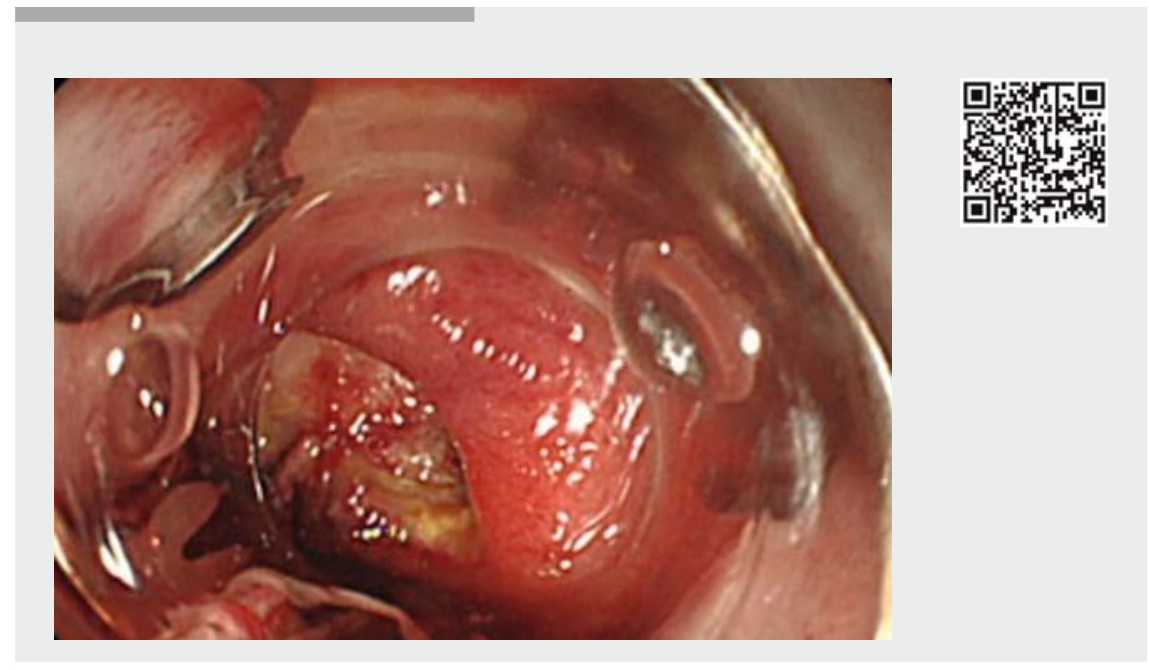

$\checkmark$ Video 1 An over-the-scope clip (9 mm t-type) was successfully deployed in a 4-yearold boy to treat intractable arterial bleeding from the anterior wall of the duodenal bulb, whereas conventional endoscopic therapies were only able to achieve temporary hemostasis.
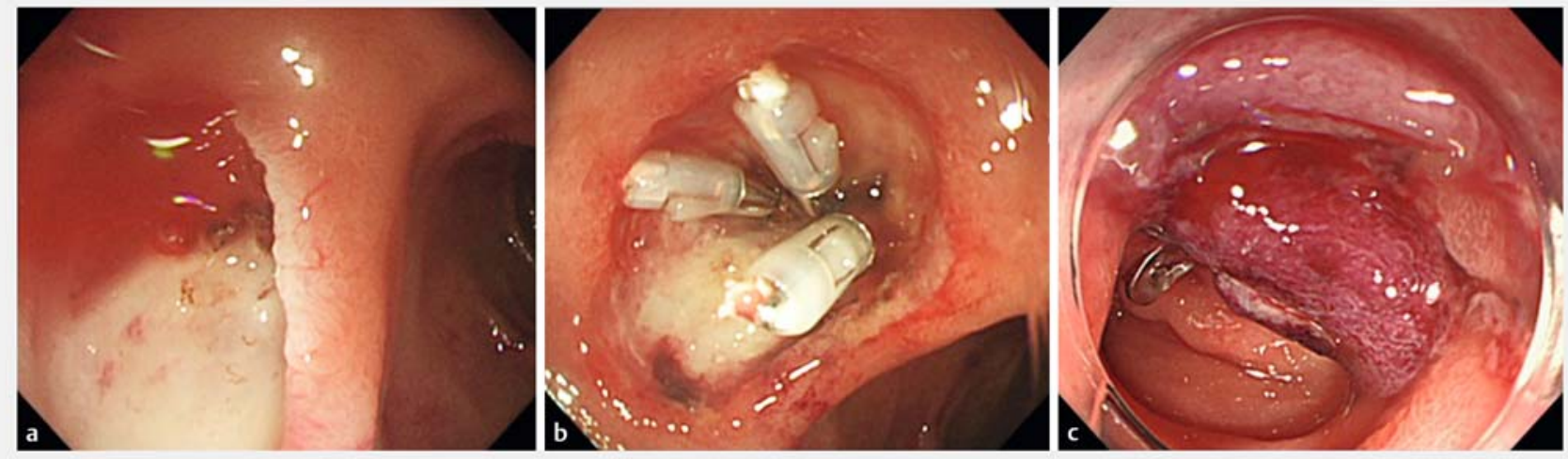

- Fig. 1 Endoscopy images from 4-year-old boy with duodenal ulcer bleeding. a Endoscopy revealed a massive bleeding ulcer in the duodenal bulb. b Conventional endoscopic therapies were effective only for temporary hemostasis. $\mathbf{c}$ The over-the-scope clip was successfully deployed at the bleeding site without any delivery difficulties in the duodenum. 


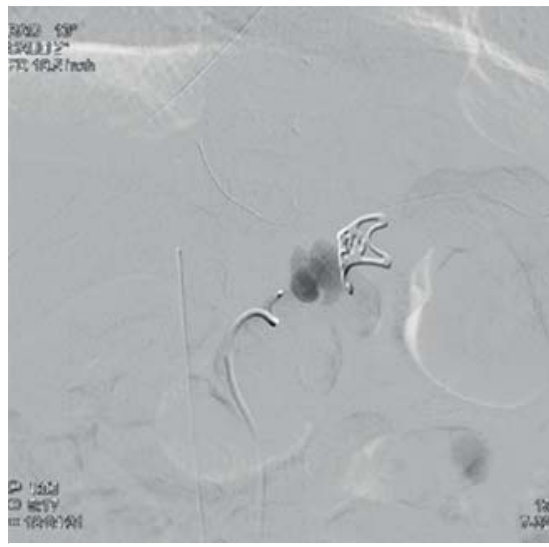

- Fig. 2 Embolization was performed on a pseudoaneurysm revealed by angiography at the sixth bleeding.

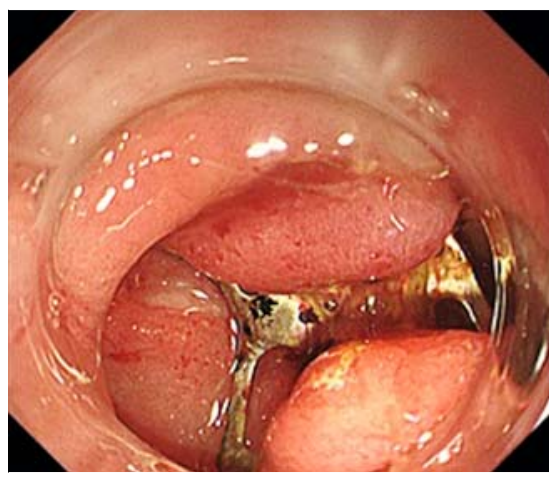

- Fig. 3 Scarring of the duodenal ulcer was apparent 3 months later.

Subsequently, 22 days later, arterial embolization was performed for the sixth recurrent bleeding episode with the presence of pseudoaneurysm, which was revealed by angiography (> Fig. 2). At 3 months later, endoscopic findings revealed scarring of the duodenal ulcer ( Fig.3). These multidisciplinary rescue therapies resulted in the patient having good outcomes without surgical intervention.

This case emphasizes that OTSC can be technically feasible for pediatric patients with lower weights and refractory bleeding.

Endoscopy_UCTN_Code_TTT_1AO_2AD

\section{Competing interests}

None

The authors

Takeo Kondo ${ }^{1}$, Hirohito Mori ${ }^{2}$, Hideki

Kobara ${ }^{2}$, Noriko Nishiyama ${ }^{2}$, Sonoko Kondo', Hitoshi Okada', Takashi Kusaka'

1 Department of Pediatrics, Faculty of Medicine, Kagawa University, Kagawa, Japan

2 Gastroenterology and Neurology, Faculty of Medicine, Kagawa University, Kagawa, Japan

Corresponding author

\section{Takeo Kondo, MD}

Department of Pediatrics, Faculty of Medicine, Kagawa University, 1750-1 Ikenobe, Miki, Kita, Kagawa 761-0793, Japan Fax: +81-87-8912172

tkondo@med.kagawa-u.ac.jp

\section{References}

[1] Kirschniak A, Kratt T, Stüker D et al. A new endoscopic over-the-scope clip system for treatment of lesions and bleeding in the $\mathrm{Gl}$ tract: first clinical experiences. Gastrointest Endosc 2007; 66: $162-167$
[2] Nishiyama N, Mori H, Kobara H et al. Efficacy and safety of over-the-scope clip: including complications after endoscopic submucosal dissection. World J Gastroenterol 2013; 19 : $2752-2760$

[3] Kobara H, Mori H, Fujihara S et al. Outcomes of gastrointestinal defect closure with an over the-scope clip system in a multicenter experience: an analysis of a successful suction method. World J Gastroenterol 2017; 23: $1645-1656$

[4] Manta R, Galloro G, Mangiavillano B et al. Over-the-scope clip (OTSC) represents an effective endoscopic treatment for acute GI bleeding after failure of conventional techniques. Surg Endosc 2014; 27: 3162 - 3164

[5] Wright R, Abrajano C, Koppolu R et al. Initial results of endoscopic gastrocutaneous fistula closure in children using an over-thescope clip. J Laparoendosc Adv Surg Tech A 2015; 25: 69-72

\section{Bibliography}

DOI https://doi.org/10.1055/s-0043-120520

Published online: 23.11.2017

Endoscopy 2018; 50: E46-E47

(c) Georg Thieme Verlag KG

Stuttgart · New York

ISSN 0013-726X

\section{ENDOSCOPY E-VIDEOS}

https://eref.thieme.de/e-videos

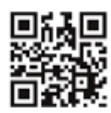

Endoscopy E-Videos is a free access online section, reporting on interesting cases and new

techniques in gastroenterological endoscopy. All papers include a high quality video and all contributions are freely accessible online.

This section has its own submission website at https://mc.manuscriptcentral.com/e-videos 